\title{
Relevance of Traditional Indian Medical Concepts in Psychosomatic Medicine
}

\author{
Mamta Sood, Saurabh K Singh, Rakesh K Chadda \\ Department of Psychiatry, All India Institute of Medical Sciences, New Delhi.
}

\begin{abstract}
Traditional medicine comprises of health related knowledge, skill and practices indigenous to different cultures. India has a rich heritage of traditional system of medicine that emphasizes the close link between mind and body like the psychosomatic medicine. The government of India has set up a department of AYUSH (Ayurveda, Yoga and Naturopathy, Unani, Siddha and Homoeopathy). The importance of life style, dietary and environmental factors in the development of various psychosomatic disorders has been emphasized in all the Indian traditional systems of medicine. Although studies have shown acceptability and beneficial role of traditional medicinal practices, efforts should be made to tease out and conduct research on the practices, which can help physicians in improving well-being of the patients. More rigorous research is required in the direction to generate evidence base for these practices so that their full potential can be realized.
\end{abstract}

Keywords: Traditional Indian systems of medicine, AYUSH, Ayurveda, ayurvedic medicine, psychosomatic disorders.

India is a country of great cultural diversity and has a rich heritage of traditional system of medicine, such as Ayurveda, Yoga, Siddha, Unani and Homeopathy. The Ayurveda, Yoga and Siddha originated in India with history going back to nearly five millennia while Unani and Homeopathy came later to India and got assimilated in Indian culture (1). These ancient systems of medicine have been described under the term traditional medicine that encompasses diverse health concepts and approaches. Traditional medicine comprises of health related knowledge, skill and practices indigenous to different cultures (2). It plays an important role in meeting health care needs of people, especially in developing countries. As per World Health Organization estimates, around $80 \%$ of the population in some of the countries in Asia and Africa seek help from traditional systems of medicine for their primary care (3).
The Indian system of traditional medicine emphasizes the close link between mind and body like the psychosomatic medicine. In both, it is important to understand the interaction between biological, psychological and social factors in the causation and treatment of a disorder. It is not only restricted to the field of psychiatry but is applicable to entire system of modern medicine (4). It is important to utilize the knowledge derived from traditional Indian medical concepts to enhance our understanding of psychosomatic medicine. The Government of India has also taken an initiative to establish the Department of AYUSH (Ayurveda, Yoga, Unani, Siddha and Homoeopathy) to promote the use and develop research in this potential areas of Indian systems of medicine (5).

In this article we will briefly discuss about the different types of traditional Indian medicine

Correspondence: Dr. Mamta Sood, Prof. Department of Psychiatry, All India Institute of Medical Sciences, Ansari Nagar, Ring Road, New Delhi - 110029. Ph: 011-26546634. Email: soodmamta@gmail.com. 
systems and their relevance to psychosomatic medicine.

\section{Basic Principles of Indian Traditional Medicine}

Ayurveda is the most ancient system of Indian traditional medicine. Ayurveda means the science of life and it is believed that, the Hindu God, Brahma gave the knowledge of healing to the sages who passed it to their disciples in form of oral recitations and writings (6). The four Vedic Hindu texts, Yajur Veda, Rig Veda, Sam Veda, and Atharva Veda formed the basis of ancient Indian medicine. The knowledge of all Vedas was compiled by Agnivesha, which was later edited by Charaka and called as "Charaka Samhita". This book is considered as the foundation of Ayurvedic medicine. The teachings of Ayurveda are based on the concepts of philosophical (Vaisheshika) and logical thinking (Nyaya) (6). The basic difference between the teachings of the two schools lies in the process of making a plan for treatment. Vaisheshika school laid emphasis on inferences and perceptions obtained from patients whereas Nyaya school focused on prior extensive knowledge about the patient's and disease condition before starting any treatment. The former classified any matter into six categories: Dravya (substance), Guna (quality), Karma (activity), Samanya (generality), Visesa (particularity) and Samavaya (inherence). According to Ayurveda, the entire universe is composed of five elements referred to as Pancha Mahabhoota (i.e. prithvi-earth, jal-water, agnifire, vayu-air and aakash-sky). The different combinations of these elements form three basic humors (Tridoshas, means three defects: body disorders due to air or gases, body disorders due to bile, body disorders due to phlegm or inflammatory exudates) of human body: Vata dosha, Pitta dosha and Kapha dosha, controlling the basic physiological functioning. The human body consists of seven tissues (Saptadhatus, means seven elements), which work, in coordination to maintain the functioning of the body. The accumulation of different waste products known as (Tri Malas, means three excretory products or toxicants) can lead to different type of infections. Another important concept is of Trayo Dosa. Agni is a biological fire of the body for all the metabolic functions. The balance between these elements of the body is essential to maintain a healthy body (7). There are four basic tenets of treatment in Ayurveda: physician, drugs, the attendant and patient. Physician offers thorough examination, medications and therapies. There are three types of therapies. Yukti vyapashraya (rational/ physical therapy) reduce three doshas and includes life-style practices, diet, herbs, and clinical methods. Sattavajaya (psychological therapy) increases sattva guna by the practice of yoga. Divya chikitsa (spiritual therapy) helps in removing karmic afflictions by rituals, mantra, gemstones, pilgrimage, asceticism and other esoteric practices (7).

Yoga is a Sanskrit word which means "the union of the individual self (Jiva-atman) to transcendental self (Parama-atman)" (8). Yoga Sutras, written by an ancient yoga teacher and sage, Patanjali, was an effort to define and standardize the practices of yoga (8); an eight fold path of yoga for better expression of true self. These are: Yama (removal of bad habits), Niyama (inculcating good virtues building a new moral behavior), Asana (postures for practicing), Pranayama (controlling breathing pattern), Pratyahara (isolating the mental activities from external world), Dharana (trying to focus on one single object), Dhyana (concentrated meditation focusing on the self) and Samadhi (transcendental super consciousness). The methodological alteration of one's consciousness results in liberation from ego successfully controlling the pathological expression of biological psychic and social parameters of illness (8). There are many variants of classical yoga defined in the Indian literature. In India, Raj yoga, Hath yoga and Mantra yoga, are most commonly practiced for treatment of psychosomatic disorders (8). In recent years, research has been carried out that has shown yoga to have multiple beneficial 
effects on bodily functions and immunity (9). This has resulted in incorporation of different yogic practices in the management of noncommunicable diseases and as part of stress relieving packages.

Siddha system of medicine is attributed to the great Siddha (Master), named Ayastiyar. Siddha comes from the word Siddhi (achievement) and Siddhars are people who practice it (10). They are believed to have achieved divine power by virtue of their knowledge. Siddha literature is in Tamil and is practised largely in Tamil speaking part of India and abroad. Some of the works by Ayastiyar are present in standard books of medicine and surgery in daily use among the Siddha medical practitioners (11). Like Ayurveda, its basic premise is that all objects in the universe including human body are composed of five basic elements (Pancha Mahabhoota, vide Supra) namely, earth, water, fire, air and sky. This system considers the human body as a conglomeration of three humours, seven basic tissues and the waste products such as faeces, urine and sweat. The equilibrium of humours is considered as health, and its disturbance or imbalance leads to disease or sickness. Minerals and metals are used as drugs in this form of medicine. The principle of using metals for treatment is based on the concept of preventing body from decomposing by using materials, which are difficult to decompose. There are 96 basic principles of Siddha $(10,11)$.

The Unani medicine has originated from Greece and is based on the teachings of Hippocrates and Galen further advanced it (1, 12). The composition of human body is constituted of seven constituents; elements, temperament, humors, organs, pneuma faculties and spirits. These components are required in correct proportions for well-being and are taken into consideration while formulating any treatment $(12,13)$. Important concepts in practice of Unani medicine are temperament (mizaj), heredity, complaints, signs and symptoms of the body, external observation, examination of the pulse ( $n u b z)$, urine and stool, etc. Various treatments include venesection, cupping, diaphoresis, diuresis, Turkish bath, massage, cauterization, purging, emesis, exercise, leeching, etc.

Homeopathy medicine was developed by Samuel Hahnemann and derives its name from two Greek words Homoios (like) and Pathos (treatment). In Homeopathy, the therapeutic modality is developed with consideration that it will produce manifestations of a disorder when administered to any individual (14). The symptoms of disorder are considered as body's natural defense mechanism and the underlying principle is to strengthen it. Homeopathy is based on two main principles. The first principle is 'like cures like'. This means that for any disorder, the homeopathic remedy should be the one that produces similar disorder in a healthy individual. The second principle is based on the dilution of medication so that its minimum dose is used. A homeopathic remedy maintains its biological activity even at small dosage and works by stimulating 'vital force' of life $(14,15)$.

Although the various traditional systems of medicine in India differ in their underlying principles, they take a holistic approach in understanding of causation and management of diseases. The basic tenant of all the systems is that the mind, body and environmental factors act in unison to cause an illness. Hence, it is important to understand contribution of each system for treatment of a disorder.

\section{Conceptualization of Psychosomatic Disorders in Indian Traditional Medicine}

Many theorists propose that the psychosomatic approach to health and disease forms the basis of Ayurvedic medicine (16). The 'Purusha' (man) in Ayurvedic science is treated as a psychosomatic entity and is constituted by the satva (mind), the atman (soul) and the sarira (body). The basic premise of healthy living in Ayurveda is to maintain a balance between mind, body and soul or consciousness. This balance 
can be achieved by having understanding about basic concepts of Ayurveda. The various psychological factors (Mansika-bhava), like kama (luster), krodha (anger), shoka (grief), bhaya (fear), irshya (envy) can affect the different humors. It results in disturbed physiological functioning of the body that may cause different psychosomatic disorders. Value based qualities of living that can act as protective factor against ill health. Increase in humors (physical factors) can also affect the mental health of human beings (17). Few noteworthy examples mentioned include increase in Vatika humors resulting in Anidra (insomnia). Similarly, Pittaviridhi causes murchha and Kapha vridhi causes Tandra (sedation) and Nidra (sleep). Many examples of psychosomatic disorders can be found in Ayurvedic texts like a clinical condition called Grahini roga, which is similar to irritable bowel syndrome (IBS) (18). The imbalance between different doshas results in dysfunction of Agni (fire) and is believed to be the cause for development of IBS. The mansikbhavas (mental feeling or thinking) like kama (luster) and krodha (anger) can affect the doshas that may result in IBS.

Yoga explains the origin of psychosomatic disorders through the concepts of Pancha Klesha (five psychological afflictions) (19). These are Avidya (failure to recognize ultimate reality leading to physical attributions), Asmita (misplaced sense of identification which can result in believing psychiatric symptoms as originating from bodily dysfunction), Raga and Dwesha (attraction and repulsion) and Abhinivesha (clinging to life due to fear of death). Avidya is major factor responsible for different Kleshas from time to time and results in stress that is the underlying cause for various psychosomatic disorders. In Siddha medicine, psychosomatic disorders find mention in the works of Yogi Chitamani (20). The book describes in great details about different neurotic and somatoform disorders. Several scholars in the field of Unani medicine have philosophized about various causes of hysteria and other psychosomatic disorders. The effects of psychological signs and systems on the body were elaborated by Ibn-e-Nafees (1210-1288 A.D.) in his book, Kulliyat-e-Nafeesi (Book on Fundamentals, written by Nafeesi) (21). He proposed that excess of black and yellow bile in body affects the mind resulting in negative emotions, which can lead to psychosomatic disorders. He suggested change in the environmental factors and use of relaxation techniques in resolution of symptoms.

These different systems have also proposed various therapies for treating psychosomatic disorders. For example, Ayurveda mentions Panchkarma as a therapy for these disorders. It is a Sanskrit word, which means five karmas (actions): Virechan (purgation), Vaman (induced vomiting), Basti or Anuvasana (use of medicated oil enemas), Rakta moksha (detoxification of blood) and Nasya (administration of medicines through nasal route). The underlying principle is to cleanse the body from disease causing factors (22). This helps in maintaining the balance between three doshas. Wide range of Ayurvedic medicinal plants are used in the management of various psychiatric disorders. In a systematic review (23), Rout et al have compiled a list of 78 drugs, which are either used in combination or as monotherapy. There is greater acceptance of these drugs amongst the patients due to their easy availability, affordability and minimum side effects even though there is lack of scientific evidence for the efficacy and safety profile of these medicines.

\section{Relavance of Indian Traditional Medical Knowledge in Treatment of Psychosomatic Disorders}

The Indian traditional systems of medicine have been used worldwide and are classified under the broad rubric of complementary and alternative medicine (CAM). In a systematic review, which included 16 studies, Fras et al found the use of CAM to be as high as $74.8 \%$ in some of studies (24). The use was higher amongst more educated middle aged women. It 
was more commonly used for psychosomatic disorders like back pain or joint pains pathologic, depression, insomnia, severe headache or migraine, and stomach or intestinal illnesses. The study also found that medical students had most critical views about CAM when compared with other health care professionals. A National population-based survey done in Australia found that $68.7 \%$ of people interviewed had had at least one form of CAM in preceding 12 months and around 45\% of them had visited CAM practitioner (25). Yoga was used by $12 \%$ of them. Meditation and homeopathy were used in $17.5 \%$ and $6 \%$ of the participants, respectively. In a similar survey done in England, lifetime and 12-month prevalence of CAM use were $44.0 \%$ and $26.3 \%$, respectively. This study also reiterated that as a group, psychosomatic disorders were the most common reason for consultation (26). The higher cost and dissatisfaction with modern medicine, along with the belief that it offers more holistic care and is devoid of side-effects, can be possible reasons for higher rates of acceptance of traditional therapies (24). The authors suggested that the future physicians should be more aware of the basic principles of these therapies so that they can meet the requirements of patients.

These methods of treatment from traditional medicine are deeply rooted in the Indian culture, and are frequently used by the patients. In India, $65 \%$ of rural population uses Ayurveda and medicinal plants for their primary health care needs (2). The concept of illness as a result of bad karma helps in accepting the pain of illness. The relationship between doctor and patient is like Guru - chela and doctor is considered as elderly figure who has to be respected (27).

The importance of life style, dietary and environmental factors in the development of various psychosomatic disorders has been emphasized in all the Indian traditional systems of medicine. In Ayurveda, the beneficial effects of exercise have been mentioned in first section
(Sutra Sthana) and in the chapter on 'Non suppression of natural urges' of the Charaka Samhita (28). Exercise as therapy has been described for at least twenty types of diseases like Trpti (anorexia nervosa), Apakti (indigestion), Gurugatrata (heaviness of the body) and other psychosomatic disorders. Shortlow graded exercise has been shown to decrease pain perception and persons with better fitness show higher pain threshold (29). Decreased pain threshold has been implicated in a number of psychosomatic disorders; hence regular exercise can be one of effective treatment strategies for dealing with somatic pain symptoms. A Dutch longitudinal study showed that lack of physical activity and sedentary life style was significantly associated with functional somatic symptoms (30).

Similarly, yoga has beneficial effects in many psychosomatic disorders. Fibromyalgia syndrome is a functional disorder in which psychosocial factors play an important role in etiology and management (31). Eight weeks of yoga therapy improved pain, pain perception as well as increased pain acceptance and mindfulness in fibromyalgia (32). The improvement was accompanied with changes in salivary cortisol levels. In a multi-country survey conducted amongst more than 2500 patients with fibromyalgia with an objective to determine their engagement with yoga practices and the perceived benefits (33), around $80 \%$ of the participants used yoga, and the most commonly cited benefits were decrease in stiffness, relaxation, and better balance. Numerous studies have shown the biological underpinnings for the beneficial effects of yoga (34), used as both a top-down or bottom-up mind-body practice. Yoga increases parasympathetic stimulation that improves the balance of autonomic nervous system. The increase in vagal activity decreases psychophysiological arousal and stress response and increases antioxidant levels decreasing oxidative stress and decreases cortisol levels.

Traditional systems of medicine pay a 
great deal of attention on quality and composition of the food. There is a common belief that some foods have 'hot', 'cold' or 'heavy' properties; these affect gunas and doshas like pitta and kapha; the resultant imbalance may produce a symptom or disease. Studies have shown that poor quality diets are often associated with depression and anxiety, which are common comorbid conditions in psychosomatic disorders (35). Although conclusive evidence is lacking in this field, it is possible that dietary modification plays an important role in management of psychosomatic disorders. For example, many guidelines for management of IBS have stated beneficial effects of dietary modification. The most common recommendations are to adhere to a regular meal pattern, reducing intake of insoluble fibers, alcohol, caffeine, spicy foods, and fat (36).

Although studies have shown acceptability and beneficial role of traditional medicinal practices, scientific community needs to take an open view while determining its utility. Every effort should be made to tease out the practices, which can help physicians in improving well-being of the patients. More rigorous research is required in the direction to generate evidence base for these practices so that their full potential can be realized.

\section{Current Status of Traditional Medicine in India}

The government of India has set up a department of Indian Systems of Medicine and Homoeopathy (ISM\&H) in 1995 with aim of recognising the alternative or the indigenous systems of medicine and simultaneously controlling, promoting and developing them. The department was renamed AYUSH (Ayurveda, Yoga and Naturopathy, Unani, Siddha and Homoeopathy) in 2003. The Government of India created a separate ministry called Ministry of AYUSH in 2014 that is headed by a minister of state (37). A recent analysis of National Sample Survey data about utilization of services by all patients seeking out-patient care in previous 15 days reported that only $6.9 \%$ of the study participants received treatment from AYUSH (38). The lower rates of utilization could be due to focus only on therapeutic use of AYUSH, thereby ignoring its use in disease prevention or health promotion. The government of India aims to promote research to generate evidence base for AYUSH through collaborative efforts and by giving financial assistance.

\section{Conclusion}

The traditional systems of medicine have a rich history and co-exist with the contemporary practice of modern medicine. Modern medical sciences have recognized the importance of mind-body interaction in genesis of psychosomatic disorders and suggest life style and dietary modification in their management. This is in tune with ancient wisdom that has always realized importance of these factors in maintaining healthy life. The very fact that these traditional medical practices are accepted by a large number of individuals worldwide should motivate systematic research in this direction. The evaluation of efficacy of these practices by modern research techniques can elucidate important facets of traditional systems of medicine.

\section{References}

1. Ravishankar B, Shukla VJ (2007). Indian systems of medicine: a brief profile. Afr $J$ Tradit Complement Altern Med 4:319337.

2. Bodeker G, Ong CK, Grundy C, Burford G, Shein K (2005). WHO global atlas of traditional, complementary and alternative medicine. Geneva: World Health Organization.

3. Oyebode O, Kandala NB, Chilton PJ, Lilford RJ (2016). Use of traditional 
medicine in middle-income countries: a WHO-SAGE study. Health Policy Plan 31:984-991.

4. Martin MJ (1978). Psychosomatic medicine: a brief history. Psychosomatics 19:697-700.

5. Shrivastava SR, Shrivastava PS, Ramasamy J (2015). Mainstreaming of Ayurveda, Yoga, Naturopathy, Unani, Siddha, and Homeopathy with the health care delivery system in India. $J$ Tradit Complement Med 5:116-118.

6. Jaiswal YS, Williams LL (2017). A glimpse of Ayurveda-The forgotten history and principles of Indian traditional medicine. J Tradit Complement Med 7:5053.

7. Rastogi S (2010). Building bridges between Ayurveda and modern science. Int J Ayurveda Res 1:41-46.

8. Singh AN (2006). Role of yoga therapies in psychosomatic disorders. Int Congress Series 1287:91-96.

9. Sharma M (2014). Yoga as an alternative and complementary approach for stress management: a systematic review. J Evid Based Complementary Altern Med 19:5967.

10. Shukla S, Saraf S (2011). Fundamental aspect and basic concept of siddha medicines. Systematic Reviews in Pharmacy 2:48-54.

11. Karunamoorthi K, Jegajeevanram K, Xavier J, Vijayalakshmi J, Melita L (2012). Tamil traditional medicinal system-siddha: an indigenous health practice in the international perspectives. Tang [Humanitas Medicine] 2:12.1-12.11.

12. Husain A, Sofi GD, Tajuddin T, Dang R,
Kumar N (2010). Unani system of medicine-introduction and challenges. Med J Islamic World Acad Sci 18: 27-30.

13. Poulakou-Rebelakou E, Karamanou M, George A (2015). The impact of ancient Greek medicine in India: the birth of Unani medicine. Acta Med Hist Adriat 13:323-328.

14. Ernst E (2002). A systematic review of systematic reviews of homeopathy. $\mathrm{Br} \mathrm{J}$ Clin Pharmacol 54:577-582.

15. Linde K, Melchart D (1998). Randomized controlled trials of individualized homeopathy: a state-of-the-art review. $J$ Altern Complement Med 4:371-388.

16. Singh RH, Sinha BN (1976). Ayurvedic concept of the psychosomatic basis of health and disease. Indian J Hist Sci 11:75-80.

17. Singh RH (1981). The psychosomatic disorders and their management in ayurveda. Anc Sci Life 1: 41-48.

18. Gupta N, Tiwari R (2015). Irritable bowel syndrome- an ayurvedic perspective. Int Ayurvedic Medical J3:2810-2813.

19. Singh S (2016). Yoga: an answer to lifestyle disorders. Int J Applied Natural Sci 5:27-34.

20. Somasundaram O (2002). Psychiatric thoughts in the Tamil culture. Indian $J$ Psychiatry 44:165-169.

21. Javed G, Anwar M, Siddiqui MA (2009). Perception of psychiatric disorders in the Unani system of medicine-a review. Eur JIntegr Med 1:149-154.

22. Conboy L, Edshteyn I, Garivaltis H (2009). Ayurveda and Panchakarma: measuring the effects of a holistic health 
intervention. Scientific WorldJ9:272-280.

23. Rout OP, Acharya R, Gupta R, Inchulkar SR, Karbhal KS, Sahoo R (2013). Management of psychosomatic disorders through ayurvedic drugs-a critical review. World J Pharmacy Pharmaceutical Sci 2:6507-6537.

24. Frass M, Strassl RP, Friehs H, Müllner M, Kundi M, Kaye AD (2012). Use and acceptance of complementary and alternative medicine among the general population and medical personnel: a systematic review. Ochsner $J$ 12:45-56.

25. Xue CC, Zhang AL, Lin V, Da Costa C, Story DF (2007). Complementary and alternative medicine use in Australia: a national population-based survey. J Altern Complement Med 13:643-650.

26. Hunt KJ, Coelho HF, Wider B, et al (2010). Complementary and alternative medicine use in England: results from a national survey. Int J Cin Pract 64:14961502 .

27. Neki JS (1973). Guru-Chela relationship: the possibility of a therapeutic paradigm. Am JOrthopsychiatry 43:755-766.

28. Mondal S (2013). Science of exercise: ancient Indian origin. J Assoc Physicians India 61:560-562.

29. Hennings A, Schwarz MJ, Riemer S, Stapf TM, Selberdinger VB, RiefW (2012). The influence of physical activity on pain thresholds in patients with depression and multiple somatoform symptoms. Clin $J$ Pain 28:782-789.

30. Janssens KA, Oldehinkel AJ, Bonvanie IJ, Rosmalen JG (2014). An inactive lifestyle and low physical fitness are associated with functional somatic symptoms in adolescents. The TRAILS study. $J$ Psychosom Res 76:454-457.

31. Häuser W, Burgmer M, Koellner V, et al
(2013). Fibromyalgia syndrome as a psychosomatic disorder-diagnosis and therapy according to current evidencebased guidelines. Z Psychosom Med Psychother 59:132-152.

32. Curtis K, Osadchuk A, Katz J (2011). An eight-week yoga intervention is associated with improvements in pain, psychological functioning and mindfulness, and changes in cortisol levels in women with fibromyalgia.J Pain Res 4:189-201.

33. Firestone KA, Carson JW, Mist SD, Carson KM, Jones KD (2014). Interest in yoga among fibromyalgia patients: an international internet survey. Int $J$ Yoga Therap 24:117-124.

34. Telles S, Singh N, Balkrishna A (2014). Role of respiration in mind-body practices: concepts from contemporary science and traditional yoga texts. Front Psychiatry 5:167.

35. Sarris J, Moylan S, Camfield DA, et al (2012). Complementary medicine, exercise, meditation, diet, and lifestyle modification for anxiety disorders: a review of current evidence. Evid Based Complement Altern Med. doi:10.1155/2012/809653.

36. Cozma-Petruţ A, Loghin F, Miere D, Dumitraşcu DL (2017). Diet in irritable bowel syndrome: what to recommend, not what to forbid to patients! World J Gastroenterol 23:3771-3783.

37. Samal J (2015). Situational analysis and future directions of AYUSH: an assessment through 5-year plans of India. J Intercult Ethnopharmacol 4: 348-354.

38. Rudra S, Kalra A, Kumar A, Joe W (2017). Utilization of alternative systems of medicine as health care services in India: evidence on AYUSH care from NSS 2014. PLoS ONE 12(5): e 0176916 . https://doi.org/10.1371/journal.pone.017 6916. 